УДК 339.5

DOI 10.18101/2304-4446-2019-1-18-24

\title{
ПРОБЛЕМЫ И ПЕРСПЕКТИВЫ РАЗВИТИЯ ЭКСПОРТА МЯСНОЙ ПРОДУКЦИИ В МОНГОЛИИ
}

\section{(C) Потаев Виктор Сергеевич}

доктор экономических наук, профессор,

Бурятский государственный университет

Россия, 670000, г. Улан-Удэ, ул. Смолина, 24а

E-mail: potaev_viktor@mail.ru

\section{() Витульева Татьяна Александровна}

преподаватель Улан-Баторского филиала,

Российский экономический университет им. Г. В. Плеханова

Монголия, 210351, г. Улан-Батор, пр. Мира, 131

E-mail: t-vituleva@mail.ru

В статье рассмотрены возможности развития в Монголии экспорта мяса и мясной продукции, в т. ч. в Россию и Китай. В последние годы страна ориентирована больше на экспорт минерально-сырьевых ресурсов, а не продуктов сельского хозяйства. Основным сдерживающим фактором увеличения экспортных поставок из Монголии являются высокие таможенные пошлины. Другие проблемы - отсутствие международной гарантии качества и безопасности продукции, ограниченные мощности переработки сырья. Структура поголовья также ограничивает экспорт. Наибольшую долю в структуре домашнего скота занимают овцы и козы, на долю лошадей и крупного рогатого скота приходится около $10 \%$. В настоящее время конина из Монголии более востребована на международном рынке. Россия и Китай также предпочитают импортировать говядину и конину из Монголии. Объемы внешней торговли монгольского мяса увеличиваются. В 2017 г. было экспортировано большое количество мяса и мясной продукции в Китай, Россию, Казахстан, Японию, Иран и Катар, при этом ежегодный объем экспорта в 2017 г. увеличился в пять раз по сравнению с уровнем 2013 г. Мясная промышленность Монголии потенциально остается одной из наиболее привлекательных отраслей реального сектора экономики страны. Перспективы развития производства мяса в стране во многом связаны с выходом на внешние рынки.

Ключевые слова: Монголия; Россия; Китай; внешняя торговля; экспорт; мясо; мясная продукция.

\section{Для цитирования:}

Потаев В. С., Витульева Т. А. Проблемы и перспективы развития экспорта мясной продукции в Монголии // Вестник Бурятского государственного университета. Экономика и менеджмент. 2019. Вып. 1. С. 18-24.

Введение. Проведение исследования внешней торговли Монголии, в частности выявление проблемных точек в экспортных поставках страны, является весьма актуальным вопросом. Монголия как страна с богатой кочевой культурой, низкой плотностью населения, огромными запасами ресурсов природного и животного происхождения имеет большой потенциал развития экспортноориентированного производства отечественных товаров. 
B. С. Потаев, Т. А. Витульева. Проблемы и перспективы развития экспорта мясной продукции в Монголии

Экспорт как составная часть внешней торговли страны имеет огромное значение для ее социально-экономического развития. Но сегодня Монголия больше ориентирована на экспорт минерально-сырьевых ресурсов, что негативно сказывается на развитии других секторов экономики, в которых имеется большой потенциал. Необходимо изучение проблемных точек, сдерживающих экспорт монгольского мяса и мясной продукции, а также определение перспектив дальнейшего развития данного сектора, в том числе через сотрудничество с ближайшими географическими соседями - Россией и Китаем.

Состояние и проблемы внешней торговли. По данным национальной статистической службы Монголии, внешнеторговый оборот Монголии за 20102011 гг. показывал рост за счет увеличения импорта и экспорта. При этом период с 2010 по 2013 г. характеризуется превышением импорта над экспортом, в 20142017 гг. наблюдается обратная ситуация, что свидетельствует о развитии национального производства и постепенной замене импортных товаров на отечественные. Торговый оборот страны за 2017 г. составил 10,5 млрд долл. США, увеличившись по сравнению с 2016 г. на 27,3\%, что может указывать на постепенное восстановление экономики Монголии в 2017 г. после кризисных лет. На экспорт пришлось 6,2 млрд долл. США, что на 26,13\% больше по сравнению с 2016 г., остальная часть пришлась на импорт — 4,3 млрд долл. США, что на 29,11\% больше, чем в прошлом году [3] (табл. 1).

Таблица 1

Внешнеторговый оборот Монголии за период 2010-2017 гг.

\begin{tabular}{|c|c|c|c|c|c|c|c|}
\hline \multirow[b]{3}{*}{ Год } & \multirow{2}{*}{\multicolumn{2}{|c|}{$\begin{array}{c}\text { Внешнеторговый } \\
\text { оборот }\end{array}$}} & \multicolumn{4}{|c|}{ В том числе: } & \multirow{3}{*}{$\begin{array}{c}\text { Баланс } \\
\text { млн } \\
\text { долл. } \\
\text { США }\end{array}$} \\
\hline & & & \multicolumn{2}{|c|}{ экспорт } & \multicolumn{2}{|c|}{ импорт } & \\
\hline & $\begin{array}{c}\text { млн } \\
\text { долл. } \\
\text { США }\end{array}$ & $\begin{array}{c}\text { темп при- } \\
\text { роста } \\
\text { цепной } \\
(\%)\end{array}$ & $\begin{array}{c}\text { млн } \\
\text { долл. } \\
\text { США }\end{array}$ & $\begin{array}{c}\text { темп при- } \\
\text { роста } \\
\text { цепной } \\
(\%) \\
\end{array}$ & $\begin{array}{c}\text { млн } \\
\text { долл. } \\
\text { США }\end{array}$ & $\begin{array}{c}\text { темп при- } \\
\text { роста цеп- } \\
\text { ной }(\%)\end{array}$ & \\
\hline 2010 & 6108,6 & 51,84 & 2908,5 & 54,26 & 3200,1 & 49,7 & $-291,6$ \\
\hline 2011 & 11415,85 & 86,88 & 4817,5 & 65,64 & 6598,36 & 106,19 & $-1780,86$ \\
\hline 2012 & 11123,5 & $-2,56$ & 4384,6 & $-8,99$ & 6738,9 & 2,13 & $-2354,3$ \\
\hline 2013 & 10627,4 & $-4,46$ & 4272,7 & $-2,55$ & 6354,7 & $-5,70$ & -2082 \\
\hline 2014 & 11011,2 & 3,61 & 5774,6 & 35,15 & 5236,6 & $-17,59$ & 538 \\
\hline 2015 & 8466,8 & $-23,11$ & 4669,3 & $-19,14$ & 3797,5 & $-27,48$ & 871,8 \\
\hline 2016 & 8274,5 & $-2,27$ & 4916,3 & 5,29 & 3358,1 & $-11,57$ & 1558,2 \\
\hline 2017 & 10536,1 & 27,33 & 6200,7 & 26,13 & 4335,5 & 29,11 & 1865,2 \\
\hline
\end{tabular}

Таблица составлена на основе данных Национальной службы статистики Монголии ${ }^{1}$

Основной причиной превышения экспорта над импортом в 2016-2017 гг. стал рост экспортных поставок животных и продуктов животного происхождения в 2 раза в 2017 г. по сравнению с 2016 г., рост от продажи минерального сырья (на 41,61\%), текстиля и текстильных изделий, преимущественно кашемира и изде-

1 Национальной службы статистики Монголии: сайт [Электронный ресурс]. URL: http://www.nso.mn/ (дата обращения: 30.12.2018). 


\section{ВЕСТНИК БУРЯТСКОГО ГОСУДАРСТВЕННОГО УНИВЕРСИТЕТА}

ЭКОНОМИКА И МЕНЕДЖМЕНТ

лий из него (на 11,74\%). Наблюдается сокращение ввоза импортных овощей, доля которых в 2017 г. составила 1,8\%, что на 1,45\% меньше, чем в 2016 г. Однако объемы импортных поставок все же превышают экспортные.

Основным барьером увеличения доли экспортных поставок из Монголии служат высокие таможенные пошлины. Таможенная пошлина, НДС и акциз России для монгольской шерстяной, кожаной и кашемировой продукции составляют до 46\% [4]. Так как мясо является главным экспортным продуктом Монголии, который выходит на рынок России, существуют большие трудности расширения сотрудничества в данной сфере и, соответственно, в развитии производства мяса и мясных продуктов. Вопросы снижения тарифов на экспорт мяса, а также вопрос создания зоны свободной торговли планируется обсудить лидерами двух стран при личной встрече $[1 ; 2]$.

Сегодня развитие животноводческих и мясоперерабатывающих предприятий по сравнению с другими отраслями более перспективно. Это связано с тем, что животноводство находится в начале цепочки производства конечного продукта. Объемы производства мяса и мясной продукции в Монголии являются значительными, что не только позволяет полностью удовлетворять внутренний спрос на мясные продукты, но также имеет потенциал для экспорта этих товаров в другие страны и возможность создания бренда «монгольского мяса» ${ }^{1}$.

Монголия активно принимает меры по развитию и расширению сотрудничества в сельском хозяйстве не только с Китаем и Россией, но и с Вьетнамом, Саудовской Аравией, Парагваем. Но наибольший интерес к такому сотрудничеству характерен для Китайской Народной Республики. Согласно данным Таможенной службы Монголии, страна в 2017 г. экспортировала большое количество мясной продукции в Китай, Россию, Казахстан, Японию, Иран и Катар, а ежегодный объем экспорта в 2017 г. увеличился в пять раз по сравнению с уровнем 2013 г. Объем экспорта мяса в 2017 г. увеличился в три раза по сравнению с предыдущим 2016 г. При этом поставки мяса крупного рогатого скота были существенно сокращены на 13,68\% в 2017 г. по сравнению с прошлым годом, поставки баранины и козлятины выросли в 11 раз, конины — в 3 раза.

Таблица 2

Структура экспорта мяса в разрезе видов и стран в 2015-2017 гг. (в \%)

\begin{tabular}{|l|c|c|c|c|c|}
\hline \multirow{2}{*}{$\begin{array}{l}\text { Экспорт мяса в разрезе видов } \\
\text { и стран }\end{array}$} & \multicolumn{3}{|c|}{$\begin{array}{c}\text { Доля в структуре } \\
\text { (в \%) }\end{array}$} & \multicolumn{2}{c|}{$\begin{array}{c}\text { Темп прироста } \\
\text { объемов поставок (в \%) }\end{array}$} \\
\cline { 2 - 6 } & 2015 & 2016 & 2017 & $2016 / 15$ & $2017 / 16$ \\
\hline $\begin{array}{l}\text { Мясо крупного рогатого скота, } \\
\text { замороженное } \\
\text { в т. ч.: }\end{array}$ & 17,87 & 7,80 & 2,05 & $-17,99$ & $-13,68$ \\
\hline Казахстан & 0,85 & 0,00 & 0,00 & & \\
\hline Катар & 0,05 & 0,00 & 0,00 & & \\
\hline Китай & 0,00 & 19,43 & 0,00 & & \\
\hline Россия & 99,10 & 80,57 & 100,00 & & \\
\hline
\end{tabular}

1 Министерство продовольствия, сельского хозяйства и легкой промышленности Монголии: сайт [Электронный ресурc]. URL: http://mofa.gov.mn (дата обращения: 30.12.18). 
B. C. Потаев, T. А. Витульева. Проблемы и перспективы развития экспорта мясной продукции в Монголии

\begin{tabular}{|l|c|c|c|c|c|}
\hline Баранина и козлятина, в т. ч.: & 0,82 & 2,67 & 8,87 & 510,26 & 1093,10 \\
\hline Иран & 0,00 & 0,00 & 99,99 & & \\
\hline Китай & 0,00 & 99,25 & 0,00 & & \\
\hline Казахстан & 89,74 & 0,00 & 0,00 & & \\
\hline Катар & 10,26 & 0,75 & 0,01 & & \\
\hline Конина, в т. ч.: & 81,31 & 89,54 & 89,08 & 206,99 & 327,16 \\
\hline Китай & 57,66 & 76,64 & 89,68 & & \\
\hline Казахстан & 0,00 & 0,14 & 1,90 & & \\
\hline Россия & 42,34 & 23,21 & 8,42 & & \\
\hline Япония & 0,00 & 0,01 & 0,0015 & & \\
\hline Всего мяса & 100 & 100 & 100 & & \\
\hline
\end{tabular}

Таблицы составлена на основании данных Таможенной службы Монголии ${ }^{1}$

В 2017 г. 89,1\% общего объема экспорта мяса составляла конина, в частности из которой было экспортировано $89,7 \%$ в Китай, Россию - 8,42\%, Казахстан $1,9 \%$, остальная часть в Японию. С начала 2018 г. доля экспорта конины сократилась от общей доли, что свидетельствует о диверсификации экспорта мяса. На втором месте экспорт баранины и козлятины (8,9\% в 2017 г.) из которого наибольшая доля пришлась в 2017 г. на Иран, в 2016 г. на Китай, в 2015 г. на Казахстан. Доля мяса крупного рогатого скота за период 2015-2017 гг. существенно сократилась, так, в 2017 г. она составила 2,1 против 17,8\% в 2015 г. Эта доля была сокращена за счет увеличения объемов экспортных поставок в пользу баранины и козлятины (табл. 3).

Таблица 3

Структура экспортных поставок пищевых мясных субпродуктов за 2015-2017 гг. (в \%)

\begin{tabular}{|l|c|c|c|}
\hline \multicolumn{1}{|c|}{ Страна } & 2015 г. & 2016 г. & 2017 г. \\
\hline Южная Корея & 0,00 & 0,00 & 0,90 \\
\hline Китай & 0,02 & 33,80 & 36,21 \\
\hline Вьетнам & 0,00 & 0,00 & 31,28 \\
\hline Казахстан & 0,00 & 0,00 & 9,80 \\
\hline Арабские Эмираты & 0,00 & 0,00 & 0,59 \\
\hline Россия & 88,87 & 0,00 & 15,64 \\
\hline Гонконг & 0,00 & 1,54 & 0,47 \\
\hline Япония & 11,10 & 64,66 & 5,12 \\
\hline Всего & 100 & 100 & 100 \\
\hline
\end{tabular}

В структуре пищевых мясных субпродуктов в разрезе экспорта из Монголии по странам за период 2015-2017 гг. значительные доли в 2015 г. приходились на Россию и Японию, в 2016 г. - на Японию и Китай, в 2017 г. на Китай, Вьетнам, Россию, Казахстан.

1 Таможенная служба Монголия: сайт [Электронный pecypc]. URL: http://www.customs.gov.mn/ (дата обращения: 30.12.2018). 
В 2018-2019 гг. планируется удовлетворить растущий спрос со стороны Ирана на «халяльное мясо» из-за ограниченного местного производства. Основными компаниями-экспортерами станут «Дархан Мит Фудс», «Мах Импекс», «Мах Маркет» и ряд провинциальных предприятий аймака Орхон. Для осуществления контроля эксперты из ветеринарной организации Ирана будут наблюдать за убоем скота и обеспечат производство мяса в соответствии с законами шариата. Для соблюдения всех правил монгольская сторона будет привлекать в качестве мясников только людей, исповедующих ислам. В Монголии к ним относятся преимущественно казахи, доля которых около $3 \%$ от всего населения страны.

Во многом благодаря новому спросу поставки баранины и козлятины достигли 2601 тонн в 2017 г., что в 11 раз больше, чем в 2016 г. И хотя это принесло в казну страны всего около 8 млн долл. США, эксперты уверены, что это только начало. Объем экспорта «халяльного мяса» в первом полугодии 2018 г. увеличился в четыре раза по сравнению с аналогичным периодом прошлого года до 775,6 тонн.

В период 2018-2019 гг. четыре предприятия из аймака Орхон планируют экспортировать 4 тыс. тонны мяса в Россию, Китай и Иран. В частности, компания «Эрдмийт» поставит 1 тыс. тонн конины в Российскую Федерацию, «Эрдэнэт мах маркет» - 500 тонн говядины в Иран, «Монгема» - 1590 тонн конины в Россию, а компания «Жаргалант мах маркет» поставит 1 тыс. тонн конины в Китай.

Рост экспорта мяса и мясной продукции приводит к повышению конкурентоспособности в мясоперерабатывающей отрасли, способствует развитию перерабатывающей промышленности в соответствии с международными стандартами и реализацией государственной политики «Мясо и молоко» [5]. Монгольское правительство намерено также содействовать экономическому росту страны путем расширения экспорта мясных продуктов.

Выводы и предложения. Проведя анализ внешней торговли Монголии, а также оценив современное состояние мясной промышленности, можно сделать вывод, что имеются определенные препятствия в активизации работ по развитию и расширению достаточно перспективной отрасли экономики по производству и переработке мясной продукции страны.

Главными проблемами по стороны Монголии в данном вопросе выступают, во-первых, отсутствие международной гарантии качества и безопасности продукции, учитывая относительно низкий уровень профилактики и борьбы с заболеваниями скота в стране.

Во-вторых, потенциал производства и культура животноводства в Монголии все еще находятся на низком уровне, так как в большинстве скотоводческие семейные хозяйства используют в основном экстенсивные методы расширения такого производства.

В-третьих, ограничение мощности переработки сырья. По данным официальной статистики, в Монголии менее половины мясоперерабатывающих заводов имеют высокую производительность, при этом часть из них не работают круглый год.

Структура поголовья также ограничивает экспорт. Наибольшую долю в почти 90\% в структуре домашнего скота занимают овцы и козы, на долю лошадей и крупного рогатого скота приходится около $10 \%$. В настоящее время конина из 
B. С. Потаев, Т. А. Витульева. Проблемы и перспективы развития экспорта мясной продукции в Монголии

Монголии более востребована на международном рынке. Россия и Китай также предпочитают импортировать говядину и конину из Монголии.

Имеется ряд барьеров и административных ограничений развития коммерческой деятельности по торговле мясом и мясными продуктами, основной проблемой выступает наличие высоких таможенных тарифов на мясо и мясную продукцию.

Проблемой также остается зависимость поголовья скота от суровых погодных условий Монголии, большие потери наблюдаются при природном явлении «зуд», когда животные не способны находить пропитание в условиях суровой зимы. Необходимо также обратить внимание на истощение земель пастбищ как последствие развития животноводства в стране. Важна и поддержка со стороны государства коренного населения, являющегося пастухами.

Объективной необходимостью выступает незамедлительное решение вышеизложенных проблем. Для этого требуется принять комплексные меры по оздоровлению скота и борьбе с инфекционными заболеваниями животных, качественному преобразованию действующей хозяйственной системы по всей вертикальной цепочке производства и реализации мяса путем создания крупных мясоперерабатывающих комплексов в стране. В будущем следует рассмотреть возможность использования индивидуальной электронной системы учета скота, а также контроля и профилактики болезней животных, улучшения племенной работы и семейных животноводческих хозяйств. Решение обозначенных проблем по вопросам диверсификации экспорта экономики Монголии возможно за счет привлечения иностранных инвестиций в страну, развития сотрудничества с ближайшими географическими соседями Монголии - Россией и Китаем, а также развитие отношений с «третьим соседом».

Стратегическими целями должны стать: усиление поддержки предпринимательства и создание системы диалога между государственным и частным секторами, защита общих интересов развития экономики страны, создание условий для свободной конкуренции на рынке мясной промышленности, информационная открытость, совершенствование менеджмента и контроля со стороны органов государственной власти.

При имеющимся огромном потенциале и возможностях экспорта, переработки мяса и производства мясной продукции Монголии необходимы совершенствование нормативно-правовой базы, грамотное ведение мясного рынка, обеспечение эффективного менеджмента в данной отрасли, а также достаточное финансирование. Мясная промышленность Монголии потенциально остается одной из наиболее привлекательных отраслей реального сектора экономики страны. Перспективы развития производства мяса в стране во многом связаны с выходом на внешние рынки. Животноводческий потенциал у Монголии огромный, так как монгольское мясо отличается своим отменным вкусом и экологичностью.

Политика развития монгольской мясной промышленности должна быть ориентирована на средне- и долгосрочную перспективу, расширение сотрудничества в области проведения совместных исследований заинтересованных сторон, разработку совместных проектов, обмен опытом в частности с российскими научноисследовательскими и учебными учреждениями.

Статья подготовлена в рамках реализации гранта РФФИ 17-22-03003 «Российскомонгольское приграничье: исследование современного состояния и проблем развития» 


\section{Литература}

1. Батзориг Б. Поддержка сельскохозяйственного сектора в качестве приоритетного сектора развития [Электронный ресурс]. URL: http://mofa.gov.mn/exp/article/entry/1159 (дата обращения: 30.12.18).

2. Потаев В. С., Кравцова А. А., Витульева Т. А. Развитие приграничных территорий как одного из направлений активизации торгово-экономических отношений между Россией и Монголией // Вестник Бурятского государственного университета. Экономика и менеджмент. 2018. № 1. С. 82-94.

3. Витульева Т. А., Кравцова А. А. Вопросы взаимодействия России и Монголии в торгово-экономической сфере // Мөнгө санхүү (Деньги и финансы). Улан-Батор : МУИС, 2018. № 1(2). С. 41-54.

4. Сосорбарам М. Томские компании проявляют интерес к импорту монгольской говядины // ARD: портал деловой информации [Электронный pecypc]. URL: http://asiarussia.ru/news/20284/ (дата обращения: 30.12.18).

5. Сосорбарам М. Халяльное мясо: Монголия готова удовлетворить растущий спрос Ирана // ARD: портал деловой информации [Электронный ресурс]. URL: http://asiarussia.ru/news/20325/ (дата обращения: 30.12.18).

\section{PROBLEMS AND PROSPECTS OF MONGOLIA IN THE EXPORT OF MEAT PRODUCTS}

Viktor S. Potaev

Dr. Sci. (Econ.), Prof.,

Buryat State University

24a Smolina St., Ulan-Ude 670000, Russia

Tatyana A. Vitulyeva

Lecturer,

Ulaanbaatar branch of Plekhanov Russian Economic University

131 Mira Prospect, Ulaanbaatar 210351, Mongolia

The article discusses the possibilities for developing the export of meat and meat products from Mongolia to other countries, including Russia and China. In recent years, the country exports mainly mineral resources, rather than agricultural products. The main limiting factor in the increase of exports from Mongolia is high customs duties. Other problems include a lack of international quality assurance and product safety, a relatively low level of prevention and control of livestock diseases in the country. Livestock culture in Mongolia is still poor, since most livestock-raising households use mostly extensive production methods, which limit their processing capacity. The livestock structure also limits exports. Sheep and goats occupy the largest share in the structure of livestock, horses and cattle accounts for about $10 \%$. Currently, horse meat from Mongolia is more in demand on the international market. Russia and China also prefer to import beef and horse meat from Mongolia. In 2017, a large amount of meat and meat products was exported to China, Russia, Kazakhstan, Japan, Iran and Qatar, and the annual export volume in 2017 increased five times compared with 2013. Meat industry potentially remains one of the most attractive sectors of the real sector of Mongolia's economy. The prospects for the development of meat production in the country are mainly associated with foreign outlet. The livestock potential of Mongolia is enormous, since, unlike many other countries exporting meat, Mongolia produce meat of excellent taste and good ecological properties.

Keywords: Mongolia; Russia; China; foreign trade; export; meat; meat products. 